\title{
Why female science, technology, engineering, and mathematics majors do not identify with physics: They do not think others see them that way
}

\author{
Z. Yasemin Kalender $\odot,{ }^{1}$ Emily Marshman, ${ }^{2}$ Christian D. Schunn, ${ }^{3}$ \\ Timothy J. Nokes-Malach, ${ }^{3}$ and Chandralekha Singh ${ }^{1}$ \\ ${ }^{1}$ Department of Physics and Astronomy, University of Pittsburgh, Pittsburgh, Pennsylvania 15260, USA \\ ${ }^{2}$ Department of Physics, Community College of Allegheny County, Pittsburgh, Pennsylvania 15212, USA \\ ${ }^{3}$ Learning Research and Development Center, University of Pittsburgh, \\ Pittsburgh, Pennsylvania 15260, USA
}

(Received 19 January 2019; published 4 December 2019)

\begin{abstract}
Gender differences in students' physics identity in introductory physics courses can influence students' interest in science, technology, engineering, and mathematics and their career decisions. Exploring the components that influence these identities is critical to developing a better understanding of the underrepresentation of women in physics courses and physics-related majors. We used a revised version of the physics identity framework developed by Hazari et al. [J. Res. Sci. Teach. 47, 978 (2010)] to investigate whether the relation between gender and physics identity was mediated by motivational factors, such as competency belief, interest, and perceived recognition by others. We surveyed approximately 500 students in introductory level calculus-based physics courses in which $30 \%$ of the students are women. Analysis revealed that the relation between gender and physics identity was mediated by students' selfreported motivation at the end of the semester. The model showed that perceived recognition by others played a major role in students' endorsement of physics identity with female students less likely to endorse statements that others perceived them as a "physics person."
\end{abstract}

DOI: 10.1103/PhysRevPhysEducRes.15.020148

\section{INTRODUCTION}

There has been much interest and effort to enhance diversity in science, technology, engineering, and mathematics (STEM) majors and careers, yet women remain underrepresented in many STEM disciplines [1,2]. Among the natural sciences, physics has shown the slowest progress in increasing the representation of women compared to other disciplines such as biology and chemistry $[3,4]$. Several interventions have been proposed to address the issue of low representation of women in physics including developing better pedagogical methods [5], improving the efficacy of physics teaching by making the curriculum relevant to all students [6], and investigating and improving students' attitudes in the physics classroom [5]. The majority of these studies has focused on students' cognitive difficulties such as understanding the physics content (e.g., problem solving, reasoning, and metacognitive skills), and on developing pedagogical strategies to address these difficulties. Moreover, there have been several other studies investigating motivational aspects of

Published by the American Physical Society under the terms of the Creative Commons Attribution 4.0 International license. Further distribution of this work must maintain attribution to the author(s) and the published article's title, journal citation, and DOI. learning physics, e.g., competency belief, interest, and recognition $[7,8]$, however, the implications of these studies have not translated into practice and reform of physics teaching and learning environments. These motivational factors can have a significant influence on learning physics [8] as well as class enrollment and decisions about students' selection of major [9].

In explaining participation in STEM careers, identity has been argued to be a particularly important motivational construct [10]. There are many forms of identity, but most relevant here is identifying with an academic domain, such as physics: students' views about whether they see themselves as a "physics person" [9-16]. Physics identity, which can shape and be shaped by students' learning experiences and classroom interactions, has been shown to predict students' career choices and outcome expectations [9-16].

Unfortunately, prior studies investigating students' physics identity indicate that male students are more likely to see themselves as a physics person [9], which may partially explain the gender differences to major in physics and career aspirations in physics-related fields [11-15]. Therefore, investigating the factors that influence physics identity may play an important role in understanding women's underrepresentation and their underperformance in introductory physics courses. Although there are several studies and frameworks regarding the nature of science identity generally [11-15], additional work is required to understand the motivational factors that influence women's 
physics identity in different physics courses. If we can understand the relations between the motivational factors that influence physics identity in different physics courses, then future work can focus on developing interventions to scaffold and support its development.

We build on prior work by Hazari and colleagues on physics identity in which they developed a framework for physics identity in high school by adapting the well-known science identity framework by Johnson et al. [11]. Previous studies have focused on documenting gender differences in some of the motivational factors hypothesized to be related to physics identity such as interest in physics, beliefs about conceptual understanding of physics and performance, and perceived recognition by others, as well as how these identities impact students' career choices for female and male students $[12,13]$. However, it is not clear from the prior work to what extent these factors relate to and interact with each other and gender in calculus-based physics courses since the context of the course can be important for the relations between these factors. Are some factors more important than others in their influence on physics identity in these courses? Do these motivational factors mediate the relation between gender and physics identity and if so, how?

To investigate these questions, we examined students' physics identities as well as the hypothesized underlying motivational constructs within the physics identity framework. Specifically, we focused on the college-level, calculus-based introductory physics courses at a large staterelated research university. Students in these classes are generally physical science or engineering majors and they are typically first-year students, so this study allows us to monitor their motivational characteristics early in their academic program. Typical for courses aimed at such majors, female students in calculus-based physics courses comprise approximately $30 \%$ of the classroom.

Our research methodology uses quantitative methods to explore which motivational factors cause changes in other factors and mediate the relation between gender and physics identity. As part of this analysis, we administered a motivational attitude survey at the end of the first physics course, a point at which students are likely to have revised their attitudes towards physics based on their first university-level course experience and it is also the point at which they are likely to reflect upon whether they should continue in physical sciences and engineering based upon their experiences (i.e., it is a very consequential moment) [17]. This work can play a role in informing the selection of strategies needed for improving students' physics learning via lowering anxiety and creating a more supportive environment.

\section{BACKGROUND}

\section{A. Sources of the gender disparity in physics}

Many research studies have focused on low representation of women in STEM fields due to societal biases and stereotypes. Seymour and Hewitt argued that the masculine image of current STEM culture is a deterring factor for those who do not identify as masculine [18]. In general, the image of a physicist is portrayed as male, which can make a woman feel less welcome and accepted in the physics community. Likewise, the lack of female role models (e.g., famous female physicists or female physics instructors) and being one of the few female students in a physics classroom can communicate to women that their gender is not appropriate for the field. In addition, physics is one of the disciplines that is believed to require a natural ability to be successful in it $[19,20]$, and the concept of being a "genius" or "inherently brilliant" is generally associated with men [21]. These two factors-the perceived masculine nature of the field and gender-based beliefs about brilliance in physics-foreground societal biases about who can excel and thrive in physics, which can impact female students' identity and dissuade them from pursuing study in physicsrelated disciplines. Archer et al. [22] investigated the impact of physics-related cultural attributions on girls' or women's decisions to pursue physics with ten years of longitudinal data and reported that science-keen girls or young women who name physics as their favorite subject slowly lose their interest due to alienation, discrimination, and gender-biased beliefs about physics.

Further, gendered beliefs, biases, and discrimination can negatively impact women and act as a stereotype threat against them, constraining their performance in the field. In particular, women may fear confirming the negative stereotypical beliefs about their gender in physics if they perform poorly and it can increase their anxiety [23-28]. Faculty members' gendered beliefs regarding the students' ability can be one reason for the negative threat that women experience [26]. One study showed that science faculty members in biological and physical sciences exhibit biases against female students by rating men significantly more competent when the curriculum vitae are identical except for the name of the student being male or female [26]. Gender-biased culture in physics and negative experiences of female students can create a "chilly" environment for women which can undermine their motivation to engage in learning within the "unwelcoming" culture of physics and other STEM disciplines [18]. For example, women are typically assigned by their male lab mates to "female roles" (e.g., recording data as opposed to collecting data or doing other menial work) in labor division in research lab experiments [27,29].

Underlying these macrolevel factors (e.g., gender biases, traditional stereotyped gender roles, discrimination against women), students' motivational attitudes and beliefs, which are shaped by societal biases and discrimination, can at least partly provide a mechanistic explanation for women's underrepresentation in STEM disciplines. Several studies in physics education have focused on students' motivational characteristics (e.g., factors such as students' interest 
in and value of science, beliefs about their competence, intelligence mindset views, sense of belonging, and identity formation) [9,30-32]. Individual variation in these factors can impact students' learning, persistence in degree attainments, and professional career choices [32-37]. While having positive attitudes can lead to better grades on exams [37] or higher rates of retention in challenging domains [7], negative attitudes, such as low self-confidence or not feeling recognized by others, can lower interest and increase disengagement from class participation [38].

In physics, researchers have developed and validated various instruments to assess students' motivational beliefs and attitudes about learning [39-49]. Investigating students' motivation in physics can provide education researchers information about how students engage (or not) in learning activities and why some students persist while others do not in physics courses.

Prior work has examined gender differences in students' motivation and attitudes towards physics such as competency beliefs $[7,8,42-46]$ and interest $[8,42,48]$ in physics. Physics identity in particular is a central motivational construct in physics education research that likely plays a critical role in students' retention in physics, e.g., among different gender groups [11]. Prior work in reducing the gender gaps in competency beliefs and promoting interest in all students has focused on using more interactive teaching approaches [50], adopting active-engagement teaching pedagogies such as Modeling Instruction [51], or describing specific classroom interventions such as value affirmation [52]. Researchers have also begun to investigate the relationship among the different factors [16], but more work is needed to examine the robustness across contexts of the factors underlying students' physics identities, particularly in introductory calculus-bases physics courses where female students are a numerical minority.

\section{B. Prior work on science identity and physics identity}

Gee's seminal framework describes identity as the 'kind of person' one is seeking to be and enact in the here and now [53]. As an example, a physics person typically associates his or her physics identity with being good at physics and math or enjoying solving physics problems, which often involves applying mathematical concepts in diverse physical contexts. Identity, therefore, is hypothesized to be influenced by motivational characteristics which can change over time with individuals' in-class and out-of-class experiences and interactions with peers, teaching assistants, and instructors in different circumstances and learning environments [11-16].

Researchers have considered a number of different perspectives on identity formation. One aspect under debate is whether identity is predominantly internal (the individual's private view of themselves) or whether it is a combination of internal and external components (i.e., includes perceptions of how others also view the individual) [54]. For example, external identities can pertain to individuals' manifestation of their identities when performing or acting out who they are in a particular classroom (e.g., in a science classroom, how students perform on the given tasks, how they display their understanding of the subject or the way they communicate in the context of science) [55].

Broadening this internal and external debate, researchers have argued about the full set of underlying factors that influence identity. One critical question is which motivational beliefs are central to an individual adopting a science identity. Carlone and Johnson's science identity framework [10] includes three interrelated dimensions: competence ("I think I can"), performance ("I am able to do"), and recognition ("I am recognized by others"). They tested their science identity framework through ethnographic study to understand the science experiences of successful women in science and science-related careers.

Hazari et al. modified the framework by adapting it to physics specifically rather than science more generally [11]. First, "competence" and "performance" were defined as students' beliefs in their ability to understand the subject, and students' beliefs in their ability to perform physics tasks [11]. Specifically, competence and performance dimensions focus on students' beliefs and perceptions about their physics-related skills, performances, or conceptual understandings rather than how students can practice and exhibit them in class, as in Carlone and Johnson's science identity framework. Second, the "recognition" variable was framed as recognition by others as being a good student in physics [11]. The use of "recognition" variable in Hazari et al.'s study was measured as students' views about the recognition from others which stresses the internalized feature of this identity component. Hazari et al. also added a fourth component: "interest" [11]. Carlone and Johnson had investigated scientists' identity among professionals who already had developed a certain level of interest in the science domain. But Hazari et al. studied students' identity formation in physics classrooms. Students typically have highly varying levels of interest in physics, and therefore it was thought to be a substantial factor in developing students' identities [11-15].

After bringing these modifications together, Hazari et al.'s physics identity framework hinges on four factors: students' interest, beliefs about their competence and performance, and their views on being recognized by others [11]. Those four dimensions of the physics identity framework together make up students' "internalized" identities. Past studies have focused on physics identities' impact on students' physics-related career choices and gender differences in high-school identities [11-16]. Also, some other work has adapted Hazari et al.'s framework to engineering and math contexts and investigated general populations of college students' physics, math, and engineering identities to relate students' engineering choices [16]. 
Since physics identities are influential in students' career choices and trajectories in physics-related fields, understanding how students' classroom experiences impact the affective factors that influence physics identity is vital $[11,16]$. Godwin et al. found in a nationally representative sample of a general population of college students across the country that their physics identities, which impacted their engineering career choices, were predicted by their interest and recognition in physics, but not by their physics performance or competence beliefs [16]. In particular, students' interest and recognition levels were predicted by their performance or competence beliefs [16]. This important study in the physics identity literature highlights the significance of getting positive recognition [16]. However, because this prior study used a general population, it is unclear whether identity has similar foundations in motivational characteristics in the specific population most likely to go on in physical science and engineering: students enrolled in first-year calculus-based physics courses. Below, we describe the framework we tested in this context, based on these past studies and foundational theories.

\section{Theoretical model of physics identity}

Here we propose a slightly reframed version of the physics identity framework and investigate calculus-based physics course takers' physics identity by gender (see Fig. 1). Hazari et al.'s performance (i.e., belief in one's ability to perform required physics tasks) and competence (i.e., belief in ability to understand physics content) dimensions are treated as two separate variables, but the factor analysis they conducted on the data of general population of college students suggested that performance or competence is actually a single latent variable [56]. Carlone and Johnson's separation of competence and performance was justified for scientists, but it may be reasonable to represent them with one single construct for a

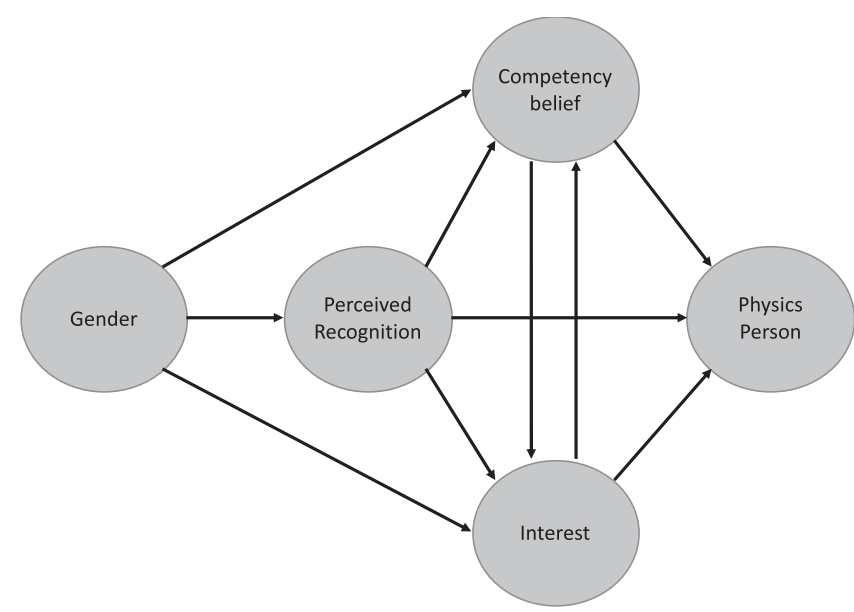

FIG. 1. Schematic representation of the theoretical framework regarding physics identity. population which has less experience within the discipline. Moreover, challenges associated with these issues also suggest that more research with different student populations in different physics learning contexts is needed.

In this investigation, our student population consists of first year college students majoring in engineering and physical science. For this population, we propose to combine these two constructs of performance and competence. Further we label the construct in terms of the more broadly used motivational construct of competency belief. This construct of competency belief is defined as students' beliefs in their capability to succeed in a certain situation, task, or particular domain [57]. Competency belief has been a central focus in thousands of educational studies, and it has been frequently found to predict students' performance even after controlling for their prior knowledge [58,59]. Students' competency beliefs have also been found to be related to career goals and enrollment in STEM courses [60], as well as the level of persistence in their academic track and long term goals $[36,61]$. Equally importantly, recent studies of competency beliefs have shown large gender differences in physics (i.e., female students with lower average competency belief than male students) $[7,8,42-45]$. The gender gap in competency beliefs also exists when comparing similarly performing female and male students $[46,47]$. These alarming trends show that female students feel less competent in physics than male students regardless of their actual performance. Because competency beliefs can influence students' interest and engagement in the classroom [36], female students' choice of pursuing physics-related careers can be negatively impacted by their lower competency beliefs. With these issues in mind, we replace competence or performance with competency beliefs for the following reasons: (i) to make the connection to the very large literature on competency beliefs; (ii) to deal with the empirical finding in both our data and in the data of Hazari et al. that competence and performance (at least as perceived by students) is really one construct rather than two separate constructs [56] at least in this population; and (iii) the construct is really about beliefs (which is clearer when competency beliefs is used as the name of the construct).

The second factor hypothesized to influence physics identity is interest. Much prior work has examined interest and its effect on motivation and learning. For example, making the science courses more relevant to students' lives and reforming curricula to promote interest in learning can improve students' achievement [62]. Interest is also well paired theoretically with the competency beliefs dimensions as connected constructs that predict students' academic outcome expectations and career aspirations within expectancy-value theory [63]. In the theory, Eccles et al. propose that expectancies of success (i.e., self-beliefs) for a domain such as physics are related to students' persistence and engagement that further impacts their course choices 
(in the short-term) and career choices (in the long-term). Value of the task is the other aspect of the theory that can enhance students' motivation and persistence in the particular task or field. Value is composed of four components: intrinsic value, attainment value, utility value, and cost. While intrinsic value explains individuals' personal interests and enjoyment in engaging with the task, attainment value refers to the importance of the task for individuals and relate to their identities. Utility value, pertains to how students can relate the task to their lives or to what extent the task can help them succeed in various fields. Finally, cost corresponds to negative aspect of engagement such as the amount of anxiety or opportunity cost due to the time spent on the task. These components of value together with expectations can impact cognitive and affective factors of academic learning. In particular, perceiving the task as valuable and connected with individuals' goals, and having an interest in the task and enjoying the task promote better engagement and motivation. We focus on intrinsic value (interest and enjoyment) and label it as "interest."

As the third factor of physics identity, we investigate the recognition by others. In particular, we use the construct of "perceived recognition," which refers to students' perception about whether others see them as a physics person or not. We believe the addition of "perceived" is important: while the perceptions held by others about the student is important, we argue that it influences the individual primarily by the extent to which those perceptions of others influence the students' perceptions of themselves and their beliefs about being recognized by others. Individuals can have biased perceptions. They can misperceive the intent of others' actions and words, particularly when viewed through the lens of societal expectations and biases. So, an act meant to support an identity (e.g., offering to help) might be viewed as denying an identity (e.g., implying lack of sufficient competence to be in the "club").

In this framework, recognition may be an important driver both of personal identity and of competency beliefs: students' classroom experiences and interactions with instructors, course assistants and peers (which shape their perception of recognition) can in turn impact their competency beliefs to achieve and class participation. In general, the motivational factors that comprise physics identity relate to and can interact with each other in meaningful ways. However, it is not clear which directions of influence are strongest or generally act as precursors to the others. For example, does interest primarily drive competency beliefs (e.g., by increasing meaningful participation which then builds competency beliefs) or do competency beliefs primarily drive interest?

Students' expectancies and values can also help them build a field-specific identity [63]. In Hidi and Renninger's four phase model of interest development, interest is influenced by competency beliefs, and it later develops into something that is recognized by others [64-66]. In research on other motivational constructs (interest, career preferences, etc.), it is indeed common to view competency beliefs as an input, and there is much empirical support for that "causal" direction [61].

However, within the research literature on competency beliefs, the focus is on the reverse causal direction: what other attitudes and experiences support changes in competency beliefs [57]. For example, Bandura's seminal competency belief theory proposes that four factors are major sources that influence one's competency beliefs. Of particular relevance to the current work, one of the sources for strengthening individuals' competency beliefs is the social or verbal encouragement and persuasion that one receives from others such as mentors, teachers, or family members (or lack of these types of positive enforcements) [57]. Therefore, based upon Bandura's theory, we test the effect of perceived recognition on competency beliefs. In other words, we hypothesize that these motivational factors are intimately intertwined in that recognition by others has an effect on the other two factors, competency beliefs and interest, which have an impact on identity.

Both expectancy-value theory and the four-phase model of interest prominently include competency beliefs (although typically called expectancy or self-efficacy there) and interest as related to identity and its development. However, expectancy-value theory does not appear to include recognition by others. The four-phase model mentions that others (e.g., teachers) can play a role during the emerging individual interest phase and there is focus on how others can support understanding or encouragement. We propose that these beliefs are particularly important for a domain such as physics that has strong sociocultural biases, e.g., pertaining to a field consisting of brilliant men, and not feeling recognized might have strong effects on one's views of self-competence and interest. We also note that if we find that recognition by others or lack thereof mediates competency belief and interest, it may be possible to change the patterns of recognition by instructors and mentors via appropriate professional development activities.

The current research was conducted in the context of introductory level calculus-based physics courses. Carlone and Johnson examined scientists' science identities whereas Hazari et al. studied physics identity of high school students as well as a general population of college students. In the context of physics at the college level, with many stereotypes about the high difficulty level, the primary pathway is unclear. Thus, some model testing work is required that examines variations of the interrelationships between the components of physics identity.

We use structural equation modeling (SEM) to investigate the sources of gender differences in identity in calculus-based introductory physics classes in which women are underrepresented. In other words, the identity framework was used to directly test the underlying 
relationship of gender to identity components through a mediation model. In a similar study conducted by Godwin et al., students' physics and math identities, and choices in engineering careers were investigated by using SEM for a general population of college students [16]. Here we specifically focus on college female and male students' physics identities in introductory calculus-based physics courses. In particular, we investigate the relation between gender and physics identity via a mediation analysis by using SEM technique. Additionally, we note that Godwin et al. compared the impact of female and male students' physics and math identities on their engineering career choices with their framework of critical engineering agency using data from nationally representative survey. In our study, we were interested in explaining the possible motivational constructs that create gendered patterns in students' physics identity in specific physics courses, i.e., calculus-based introductory physics courses for physical science and engineering majors, in which women are severely underrepresented.

We hypothesize that physics identity components in the framework will be correlated to each other and further have a mediating role in the gender and physics identity relationship. Within this framework, we posit the following central research question: To what extent can gender differences in student's identification with physics be explained in terms of gender differences in physics competency beliefs, physics interest, and perceived recognition as a physics person by others in the introductory level calculus-based physics courses? In particular, can the origins of differences in identification with physics be traced to differences in these components? As noted, Godwin et al. have examined the interaction between the motivational constructs, identity, and engineering choices using a multigroup SEM analysis for a general population of college students [16]. However, this prior work did not investigate the possible variations related to the predicting strength of each identity component (i.e., competency beliefs, recognition, and interest) on physics identity for students in calculus-based introductory physics courses, which is a population of majority male students. Therefore, we aim to explore potential variations between key components of identity across gender.

\section{METHODOLOGY}

For the current study, a survey covering the motivational constructs in the theoretical framework was administered to 559 students at the end of the semester of a calculus-based physics course. Primarily, quantitative methods were used to provide converging analysis in addressing the central research question.

\section{A. Participants}

The 559 participants completing the surveys were students enrolled in one of four different sections of introductory calculus-based physics, which is generally taken by engineering and physical science students in their first year of undergraduate studies. The university provided students' demographic information such as age, gender, ethnicity or race, and academic major as part of a larger research study using an honest broker process. Both sets of data-demographic and survey responses-were linked by the honest broker representative. During this process, an identification number was given for each student that was based on a hash function of their university email or student ID number. Therefore, the researchers only had access to the demographics data in this de-identified form.

Note that the gender data provided by the university records included only binary options given as "female" or "male." We understand that gender identity is a sociocultural and nonbinary construct with multiple associated dimensions, but we are limited to binary gender data in this study. Based on this university data, the survey participants were $33 \%$ female and $67 \%$ male students; one student did not have a reported gender status and was excluded from further analysis. In terms of ethnic or racial distribution, students were $77 \%$ White, $11 \%$ Asian, $4 \%$ Latinx, 3\% Black, $4 \%$ Multiracial, and $1 \%$ other. Regarding academic majors, $61 \%$ of students were in engineering track and $39 \%$ of students were in physical science majors. Also, $90 \%$ of the students were in their first year with an average age of 19 .

\section{B. Survey instruments}

We used the motivational surveys of identity, perceived recognition, competency beliefs, and interest based on prior instruments related to students' motivational characteristics associated with physics [8]. There were other constructs in the survey, but we focus on these four. The survey questions for each construct are given in Table I. The scales were adapted from existing motivational research in physics which was discussed in detail in our prior works $[8,42]$, and the validity of several of the scales examined here were reported in our previous work [8]. The physics identity scale was added later, and therefore additional psychometric validation (CFA results) for that scale is reported in Table I. The prior survey validation and refinement work involved iterative use of exploratory factor analysis (EFA) and one-on-one student interviews both with introductory and graduate level students $[8,42,46]$. We also performed item response theory (IRT) to check the response option distances for survey constructs [67]. The parametric grades response model (GRM) by using software STATA was used to test the measurement precision of our response scale [68]. Some of the items have response scales of "strongly disagree, disagree, agree, and strongly agree" while other items had response scale "NO!, no, yes, YES!". GRM calculates the location parameter for each response and calculates the difference between the locations. For the first group-strongly disagree, disagree, agree, and strongly agree-the response scale discrimination values were 1.2 
TABLE I. Survey questions for each of the motivational scales, along with CFA item loadings (Lambda and $p$ values of the significance test for each item loading).

\begin{tabular}{llc}
\hline \hline Construct and Item & Lambda & $p$ value \\
\hline Physics identity [11] & 1.000 & $<0.001$ \\
I see myself as physics person & & \\
Physics perceived recognition [11] & 0.914 & $<0.001$ \\
My parents see me as physics person & 0.899 & $<0.001$ \\
My friends see me as physics person & 0.660 & $<0.001$ \\
My TA or Instructor see me as physics person & 0.662 & $<0.001$ \\
Physics competency beliefs [39,70-72] & 0.723 & $<0.001$ \\
I am able to help my classmates with physics in the laboratory or in recitation & $<0.001$ \\
I understand concepts I have studied in physics & 0.722 & $<0.001$ \\
If I wanted to, I could be good at physics research & 0.720 & $<0.001$ \\
If I study, I will do well on a physics test & 0.710 & \\
If I encounter a setback in a physics exam, I can overcome it & & \\
Physics interest [70] & 0.652 & $<0.001$ \\
I wonder about how physics works & 0.772 & $<0.001$ \\
In general, I find physics & 0.786 & $<0.001$ \\
I want to know everything I can about physics & 0.803 & $<0.001$ \\
I am curious about recent physics discoveries & 0.746 & $<0.001$ \\
I want to know about the current research that physicists are doing & &
\end{tabular}

and 1.4. For the second group- "NO!, no, yes, YES!"- the values were 1.6 and 2.1. The numerical values for the location differences for item responses need to be roughly similar, as they are for both of these scales, in order to support use of means across ratings [67-69].

Additionally, we checked the interreliability for the perceived recognition items. This construct of the theoretical framework relates to students' perception of how others view them as a physics person. The survey included three separate items (Cronbach's $\alpha=0.86$ ) for family, friends, and TA or instructors, respectively. Moreover, this construct focuses on the respondents' beliefs about being recognized, and therefore is called perceived recognition and is appropriately answered by the respondent rather by another individual.

Each of the identity and perceived recognition items involved a four-point Likert response on the scale: strongly disagree, disagree, agree, and strongly agree. "I see myself as a physics person" constitutes the core internal physics identity construct and corresponds to students' beliefs and self-perception in how they designate themselves as a physics person [11]. The survey initially had two identityrelated items. However, after an initial factor analysis, we omitted one of the items: "I see myself as scientist/engineer" since it was not loading with the identity construct (or any other construct in the survey).

The competency beliefs component of our framework was captured by five competency belief items (Cronbach's $\alpha=0.83$ ) sampling different manifestations of perceived competence in academic physics (e.g., understanding and performing in various ways) [39,70-72]; they were all answered on a NO!, no, yes, YES! scale that has good psychometric properties and a low reading load, which is important for accurately measuring attitudes of students for whom English is not their native language or have other reading difficulties. In particular, this scale was used as opposed to strongly disagree, disagree, agree, strongly agree because students interpret these rating scales appropriately and because it reduces students' cognitive load, which is especially important for non-native speakers and for questions that ask raters to consider subtle differences in survey items [73].

The final construct in the framework is interest, which refers to positive affect towards doing physics-related activities and being curious about the physical world [70] and was measured with five items (Cronbach's $\alpha=0.86$ ). The question "In general, I find physics:" had response options "Very boring, boring, interesting, Very interesting" whereas the question "I wonder about how nature works" had temporal response options: "Never, Once a month, Once a week, Everyday." The remaining three items were answered on the "NO!, no, yes, YES!" scale. Varying the response scale can lead respondents to slow down and read the items more carefully.

For each survey item, students were given a score from 1 (low) to 4 (high), with higher scores indicating greater levels of interest, competency beliefs, perceived recognition and identity. Mean scores across items were calculated for items in each scale. For example, a student who answered "Yes!" to three of the competency belief questions and "no" to the other two competency belief questions would have an average competency beliefs score of $(4+4+4+2+2) / 5=3.2$. IRT analyses were previously conducted with these scales to show that the psychological distance between adjacent response items and across items was roughly similar; further more 
complex factor scores derived from IRT or CFA are so highly correlated with the mean score that there is no practical advantage in using the more complex methods [8].

\section{Quantitative analysis of survey data}

In this section, we describe our analysis approach to examine whether there are gender differences in identity. We conducted Multivariate analysis of variance (MANOVA) on students' identity, competency beliefs, interest, and recognition scores comparing female to male students. Simple Pearson correlations between constructs provided an initial validation of the proposed theoretical framework.

To provide quantitative validation test of the instruments or separability of the constructs in the current dataset, we performed a confirmatory factor analysis (CFA) on identity and the identity components (perceived recognition, competency beliefs, and interest). The model provides a good fit to the data if fit parameters are above certain threshold measures. Commonly reported fit parameters are the comparative fit index (CFI), which compares the fit of the proposed model to the null model; Tucker-Lewis index (TLI), which compares the fit of the proposed model the null model but also taking into account the complexity of the proposed model; standardized root mean square residual (SRMR), which is the standardized difference between the observed correlation and the predicted correlation; and root mean square error of approximation (RMSEA), which is the absolute fit of the model to the data taking into account the amount of data available. CFI $>0.90$, TLI $>0.90$, SRMR $<0.08$, and RMSEA $<$ 0.08 (mediocre fit $<0.10$ ) are considered acceptable fit parameters [74]. However, recent literature considers more stringent cutoff points in which RMSEA $<0.08$ is moderate and $<0.06$ is acceptable fit [75].

To quantify the significance and relative strength of the hypothesized path links between gender, identity components, and physics identity with the survey data, we used structural equation modeling (SEM), with a maximum likelihood estimation method vis-à-vis lavaan package in R [76]. Simultaneously estimating all the model links within SEM (rather than separately with different regression models) increases the statistical power of the analysis and produces estimates for the strength of different paths within the model (e.g., the contribution of competency beliefs to the gender differences in identity).

The same model fitness parameters as with CFA are examined to find a model which produced an acceptable fit to the data: CFI, TLI, SRMR, and RMSEA. We began with the saturated model and then created model variations by dropping connections or variables of low strength. We used modification indices which suggested certain links between constructs to improve the model fit, but we only used the suggestions that were theoretically plausible. $\mathrm{R}$ lavaan package has a built-in function that was used to calculate modification indices based on a given fit measures and give suggested links (positive or negative) between the variables. In the final model, data from 517 students were included in the analysis because $7 \%$ of the initial population had some missing responses.

We also calculated the indirect effects between gender and physics identity after we ran the SEM model. Indirect effect calculations estimate the strength of the mediation between the causal variable (e.g., gender) and the outcome variable (in our case, physics person) through hypothesized mediators (e.g., perceived recognition). The indirect effect of gender is calculated by multiplying the coefficients along a given path (i.e., from independent variable to mediator and from mediator to dependent variable). Since there can be multiple paths between a given independent and dependent variable through different mediators, the total indirect effect is calculated as the sum of the contributions through each path. The total indirect effect shows how much of an overall effect is produced by the given set of mediating variables. Examination of the strength of different paths shows the relative contribution of each mediator.

\section{RESULTS}

\section{A. Test of the measurement model factor structure}

The CFA conducted on the proposed model produced an acceptable fit to the data: $\mathrm{CFI}=0.975(>0.90)$, TLI $=$ $0.968(>0.90)$, SRMR $=0.035(<0.08)$, and RMSEA $=$ $0.054(<0.08)$. Thus, there is quantitative support for dividing the four constructs as proposed. Further, the factor loadings for each component were higher than 0.7 , which is considered as acceptable (see Table I). Therefore, each of the items in the survey were good items for each of their respective constructs.

\section{B. Gender and physics identity mediation model}

As shown in Table II, female students had lower scale means than male students on physics identity with a medium effect size [77]. On average, female students' responses were close to "no" on the scale whereas on average male student's responses were close to "yes" on the scale. All three motivational factors also showed lower scores for the female students with similar effect sizes. MANOVA Wilk's lambda test showed significant gender differences with $F$ $(4542)=16.70, p<0.001$. In addition, as shown in Table III, each of the variables was strongly correlated with each other as expected within the theoretical framework. But the intercorrelations were not so high that the constructs could not be separately examined in the SEM. Thus, the pattern of gender differences and intercorrelations were consistent with the overall framework and the SEM would be needed to unpack whether each of the foundational constructs contributed towards explaining the gender differences in physics identity. 
TABLE II. Descriptive statistics for female and male students in which $M$ stands for construct mean value, SD is the standard deviation, and $N$ is the number of students. Effect sizes and $p$ values are presented in the rightmost column where ${ }^{* * *}$ indicates $p<0.001$ and the minus sign indicates male students have higher scores than female students.

\begin{tabular}{|c|c|c|c|c|c|c|}
\hline \multirow[b]{3}{*}{ Construct } & \multirow{2}{*}{\multicolumn{2}{|c|}{$\begin{array}{l}\text { Females } \\
N=182\end{array}$}} & \multirow{2}{*}{\multicolumn{2}{|c|}{$\begin{array}{c}\text { Males } \\
N=365\end{array}$}} & \multirow{2}{*}{\multicolumn{2}{|c|}{ Statistics }} \\
\hline & & & & & & \\
\hline & $M$ & SD & $M$ & SD & Cohen's $d$ & $p$ value \\
\hline Physics identity (physics person) & 2.1 & 0.9 & 2.6 & 0.8 & -0.6 & $* * *$ \\
\hline Perceived recognition & 2.2 & 0.8 & 2.6 & 0.7 & -0.5 & $* * *$ \\
\hline Competency beliefs & 2.6 & 0.6 & 2.9 & 0.5 & -0.6 & $* * *$ \\
\hline Interest & 2.7 & 0.7 & 3.1 & 0.6 & -0.7 & $* * *$ \\
\hline
\end{tabular}

TABLE III. Zeroth order correlation coefficients of the constructs in the mediation model.

\begin{tabular}{lcccc}
\hline \hline Observed variable & 1 & 2 & 3 & 4 \\
\hline 1. Physics identity (physics person) & $\ldots$ & $\ldots$ & $\ldots$ & $\ldots$ \\
2. Perceived recognition & 0.79 & $\ldots$ & $\ldots$ & $\ldots$ \\
3. Competency beliefs & 0.64 & 0.65 & $\ldots$ & $\ldots$ \\
4. Interest & 0.65 & 0.60 & 0.54 & $\ldots$ \\
\hline \hline
\end{tabular}

We initially tested a moderation relation between variables and performed a multi-group SEM analysis between female and male students in order to see if the relationships between the motivational variables (perceived recognition, competency beliefs, interest and physics identity) were different across gender. There was no group difference as a result of moderation analysis at the level of weak and strong measurement invariance and at the level of regression coefficients, so we proceeded with mediation analysis using SEM (see the Appendix for detailed multigroup SEM analysis results).

The results of the SEM are presented visually in Fig. 2. The model fit indices suggest an excellent fit to the data (acceptable fit thresholds in parentheses): $\mathrm{CFI}=0.942$ $(>0.90)$, TLI $=0.927(>0.90)$, RMSEA $=0.075(<0.08)$, and SRMR $=0.046(<0.08)$. Figure 2 presents the standardized coefficients between each of the variables, and all were statistically significant. From a mediation perspective, it is noteworthy that when all of the predictor variables are entered in the model, the fit of the model with the gender variable connected directly to the physics identity gives poor fit parameters $(\mathrm{RMSEA}=0.11>$ 0.08). That is, the relation between gender and physics identity is mediated by the intervening variables that are given in our initial theoretical framework; female students appear to have a lower physics identity because they have lower levels of physics perceived recognition and interest which in turn strongly drives competency beliefs, which, together with perceived recognition and interest, strongly drives physics identity. Since the strength of the relationships between the components to physics identity were unequal, we also calculated the amount of the gender effect flowing through each of the three key motivational constructs by comparing indirect effects to one another. We calculated the indirect effects by multiplying the coefficients of different paths for each of the model constructs

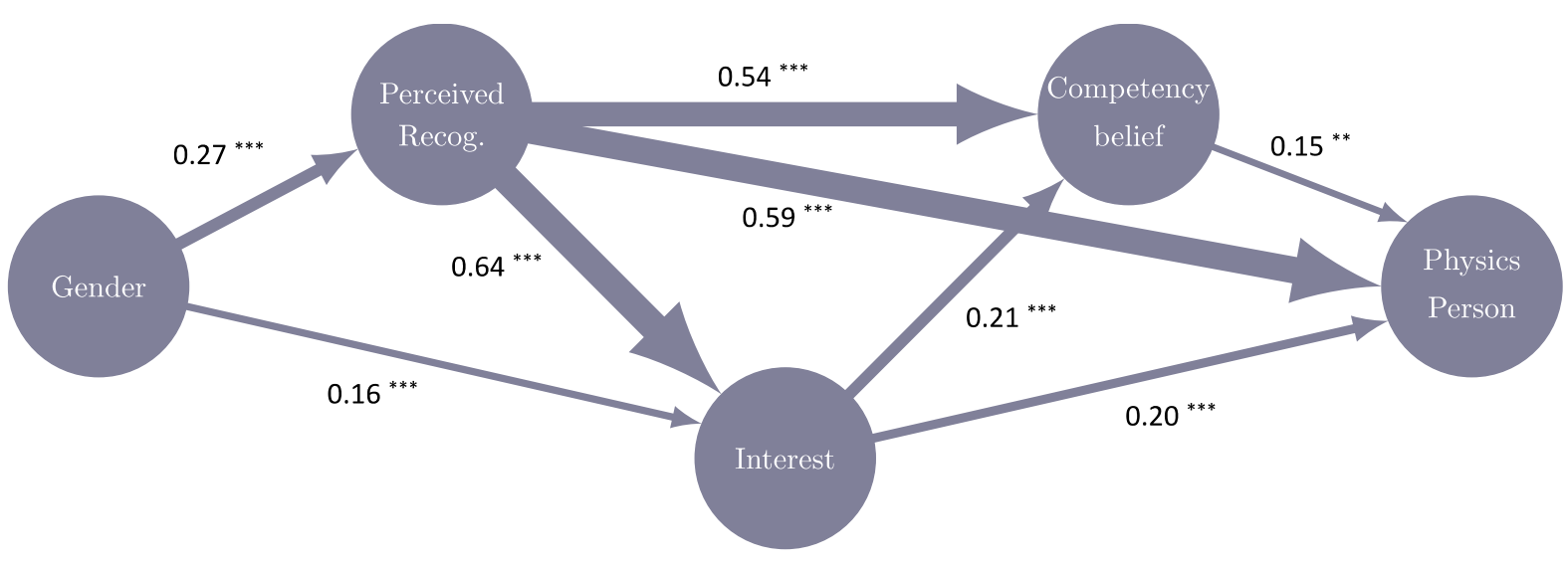

FIG. 2. Results of the structural equation modeling between gender and being a physics person through competency beliefs, interest, and perceived recognition. The line thickness corresponds to the magnitude of $\beta$ values (standardized regression coefficients), $p$ values $<0.001$ are indicated by ${ }^{* * *}$, and $p$ values $<0.01$ are indicated by ${ }^{* *}$. 
that had a direct connection to physics person. For instance, competency beliefs' indirect gender effect was calculated by adding two paths: one via perceived recognition and one via interest. For example, for the first path, we calculated 0.27 (gender $\rightarrow$ perceived) $\times 0.54$ (perceived $\rightarrow$ competency beliefs) $\times 0.15$ (competency beliefs $\rightarrow$ physics person $)=0.022$. All of the indirect effects are statistically significant, and perceived recognition had by far the largest indirect effect $\left(0.16^{* * *}\right)$, followed by interest at approximately half the size $\left(0.07^{* * *}\right)$, and competency beliefs with less than one-fourth the size $\left(0.034^{* * *}\right)$.

\section{SUMMARY AND DISCUSSION}

In this study, we investigated the roles that competency beliefs, interest, and perceived recognition play in forming physics identities for male and female students in the calculus-based introductory physics classes that are recognized as gateway courses in college for physical science and engineering STEM majors and careers. The tested physics identity model aimed to capture the interrelationships between several closely related motivational constructs and physics identity and supports earlier work by highlighting the nuances within a specific population consisting of college calculus-based introductory physics students. As hypothesized, we found support for four separable, independent factors for this sample. Consistent with prior work [78], we have found significant gender differences, where male students scored higher than female students on all four factors. These differences suggest that female and male students' identity development may show differences since students' attitudes in physics learning like competency beliefs are influenced in a different way throughout the course.

Most importantly, the results provided support for a hypothesized mediational explanation of the gender disparity in physics in terms of the underlying identity components. Godwin et al. found in a general college population that recognition by others was important for developing a physics identity, but there was no direct effect of competency beliefs on identity [16]. Here we explored how these constructs are related to one another in the physical sciences and engineering population found in calculus-based physics courses. Since disciplinary identity can be context dependent and the factors may relate to each other differently depending on the context, we tested the particular relations among the factors to see which predict variance in the physics identity in calculus-based physics courses. These analyses revealed relations of these factors to identity, whose causality can be more directly tested in future work. Identifying such relations provides opportunities for future work to test interventions designed to support identity development.

Not only did all four components show similarly sized gender differences; the path model partially explained the gender gap in physics identity. The analysis showed how gender was related to recognition and interest and more importantly how recognition is related to interest and competency beliefs. It is also interesting to note that some relations were not present in the final SEM model. For example, there was no direct relation between gender and competency beliefs (much of that relation appears to flow through recognition by others). This relation is consistent with the theory that external feedback plays critical role in competency belief development. Women in calculus-based introductory physics appeared to not see themselves as a physics person because they thought others did not see them as a physics person.

Our findings suggest that there are perceived differences between female and male students' experiences and interactions in calculus-based physics classrooms. These gender differences in students' perceived classroom experiences impact their motivational characteristics. Female students may experience a decrease in interest and develop lower competency beliefs than male students that may further shape their physics identities in negative ways and can cause gendered patterns in STEM majors and career decisions. These results have implications for both theories of identity and motivation. Building on prior work, this work adds to the theory of physics identity by improving understanding of the motivational factors underlying women's physics identity formation in calculus-based introductory physics. In particular, consistent with early work, we also have shown connections between motivational constructs like recognition by others, competency beliefs, interest, and identity in the context of calculus-based introductory physics courses which could be integrated or revised in the four-phase interest model and in expectancy-value theory.

\section{IMPLICATIONS}

Our identity model for calculus-based introductory physics suggests a causal relationship between the variables impacting students' physics identities. Through this analysis, we have shown that gender differences in students' perceived recognition influence their competency beliefs, and interest. These gender differences in students' perceived recognition, competency beliefs, and interest ultimately affect their identity in physics. One of the results in this model is the strong effect of perceived recognition on students' other motivational beliefs (i.e., competency beliefs, interest, and identity). Furthermore, students' perceived recognition exhibited a large gender gap where women's perceived recognition scores corresponded to a negative attitude (i.e., women mostly disagree that others recognized them as a physics person). This result highlights the need for designing and implementing classroom interventions targeting these issues.

A recent study found that students' physics identity was positively impacted by teachers' implementation of strategies in the classroom to increase students' perception of 
recognition [79]. Getting meaningful recognition from instructors becomes an especially important factor to support women's motivation and engagement when we consider the lack of female role models and teachers in the physics community. Equally importantly, teaching assistants (TA) who facilitate lab courses and recitations also can play a key role in supporting female students' belongingness and perceived recognition. In fact, TAs may have more opportunities to interact with students at a personal level because they teach smaller student groups in recitations and labs.

It is possible that women may have negative experiences regarding receiving recognition from their instructors and TAs. The quantitative results given in Table II showed that both female and male students reported a mean score of recognition and physics person below a positive threshold (i.e., score of 3). However, women had much lower scores for the constructs of perceived recognition and identity as a physics person, which corresponded to a negative response (i.e., score of 2 corresponds to disagreeing with the statement that others see them as a physics person). When we did the validation of the survey via student interviews, one female student shared her experience in the recitation by stating that when she asked the TA about a particular problem, her TA responded with a comment like "oh, that is an easy question!". That student noted that she felt that her question was devalued in front of the entire class and she felt stupid. She never asked another question in the recitations for the rest of the semester, which emphasizes the essential role of instructors' and TAs' explicitly supportive or perceived nonsupportive attitudes in maintaining women's active engagement and sense of belonging in physics courses. We note that to give the benefit of the doubt to the TAs, they may not mean anything negative about a student's intelligence when they say that the problem is easy and may respond similarly to men and women. However, due to societal stereotypes about women in a physics class, male and female students may internalize such responses very differently. Moreover, in calculusbased introductory physics courses in which women are underrepresented, such stereotypes may cause an even larger threat for female students when their questions are devalued (negative perceived recognition), and then their competency beliefs and physics identity can plummet.

At a broader level, the American Physics Society (APS) and the American Association of Physics Teachers (AAPT) have started to create organizational spaces for women in physics to come together and discuss the current issues to improve diversity, equity, and inclusion in physics [80,81]. Moreover, the APS has also been giving Women in Physics Awards to acknowledge the success of accomplished women in the field in order to support women's advancement. However, we argue that there are instructional level strategies that need to be implemented and improved to recruit and retain more women at the undergraduate level.
The investigation presented here suggests that students' perception of receiving recognition from the TA or instructor and peers played an important role in their positive physics identity, and female students in calculusbased introductory physics had lower perceptions of being recognized than did male students. While small gestures of recognition can have a large positive effect on women's persistence in the field, not receiving any recognition can be interpreted by female students as an indication of a lack of skills or ability since they are a minoritized groups in physics and more susceptible to negative interpretation in such ambiguous situations. Eileen Pollack, who graduated from Yale with a B. S. degree in Physics in 1978, discusses why she pursued a career in writing and being a novelist instead of her dream: getting a Ph.D. from Princeton in physics. She noted, "not a single professor-not even the adviser who supervised my senior thesis-encouraged me to go to graduate school." She continues, "Certainly this meant I wasn't talented enough to succeed in physics, I left the rough draft of my senior thesis outside my adviser's door and slunk away in shame" $[82,83]$. Years later, she met with her advisor while writing her book and asked what he thought of her undergraduate thesis project. He responded that "it was exceptional" and Pollock wondered "why had he never told me?"

So, how can we improve mentor-mentee or studentteacher interactions in physics? One approach involves organizing professional development workshops to train graduate teaching assistants and course instructors, in which they learn about underrepresented groups' experiences and their vulnerability in unsupportive classroom environments [84]. These training programs can give some guidance and provide certain strategies in terms of how the TA or instructor communicates with minority groups. Currently TA or instructor training workshops do not typically focus in any depth on equity and inclusion issues and the motivational constructs that can severely impact students' learning and can have major implications for diversity, equity and inclusion in physics classrooms.

Another approach involves using brief socialpsychological classroom interventions. These interventions, e.g., mindset or sense of belonging interventions, are typically done at the beginning of the semester and have been found to boost women's self-confidence and interest in physics, and to reduce the possible stereotype threat in the classroom [85-88]. Incorporating these types of classroom interventions into teaching can increase women's sense of belonging and competency belief and may help them develop positive feelings of recognition by peers and instructors. To address the issue raised in this study, we have recently implemented a 25 -minute mindset-belonging intervention in the second week of a calculus-based Physics 1 course during the recitations. Our preliminary results showed promising outcomes in terms of women's performance: While the control group showed large gender gap in 
Physics 1 performance, this gap was eliminated in the intervention group [88].

Academic and personal support such as family encouragement or peer and faculty relationship and mentoring by faculty can increase the persistence of women and particularly women of color in STEM fields [89-93]. Ong et al. [91] suggests that supportive mentoring relations with the faculty can be crucial but rarely provided for minority groups in STEM disciplines such as women of color. Relatedly, cultural attributions or gender roles in society can be another important aspect that can generate differences in students' motivational characteristics and identities, in particular STEM fields [89,94,95]. These biased attributions include sociocultural expectations (e.g., culturally endorsed image of a physicist as "male") and negative stereotypes (e.g., beliefs about men being better at physics than women). Women experience implicit and explicit biases and stereotypes far before they come to college [24]. Instructors' inclusive teaching strategies can help to mitigate this negative threat that many women may experience in physics [80]. Relatedly, one study has found that incorporating discussion sessions about the underrepresentation of women in physics improved female students' physics identities whereas it did not change male students' physics identity [96]. In contrast, women can have a lower sense of belonging and confidence in physics if instructors exhibit unsupportive, biased attitudes, and discriminating behaviors. In such an unwelcoming learning environment, many women can lose their interest further and disengage from course activities which can result in withdrawing from the course and possibly from a STEM major altogether because of these types of experiences [97].

Hulleman and Harackiewicz' values affirmation intervention in classroom increased students' interest and exam performance in the course especially for low performers [98]. The positive impact of such interventions on students' interest and course performance can also increase in students' identity in the domain [86]. Female and male students exhibit differences in the value they attribute to certain practices and activities. When teaching, it is important to take into account both group's interest, values, and achievement goals.

In summary, gender-based differences in physics identities and other motivational factors can reflect the gendered trends in physics and other related STEM disciplines. Gender biased attributions about brilliance, stereotype threat, and the emphasis on masculinity in the culture of physics can negatively impact physics identity and potentially lead to less participation and retention of women in physics-related majors and careers. Enhancing gender inclusivity in the physics community and other male-dominated STEM fields can improve women's physics identity and identity in other STEM fields and may yield benefit to women and the STEM discipline itself. Therefore, the issue surrounding the lack of diversity in physics and other science and engineering fields needs urgent action from educational researchers, practitioners, and policymakers. In this regard, fostering women's discipline-based identities in STEM can help increase the retention and advancement of talented and competent women in the STEM disciplines.

\section{FUTURE DIRECTIONS AND LIMITATIONS}

With the findings presented here, it is also imperative to ask what might be causing the differences in female and male students' motivational characteristics and identities and how we may be able change these patterns. In the future studies, we also intend to investigate how measures of performance, such as high school GPA or standardized test scores (i.e., SAT or AP) or physics course grades in college, can interact with students' physics identities. Although it is a common practice in the research literature on identity, using only one item to measure students' identity may incompletely measure the construct, and future studies should consider including other related items for measuring students' physics identity.

Future studies should also examine different physics classrooms that vary in terms of student demographics, teaching style, and physics course content. Investigating how physics identity can be influential for nonscience major students or health science students such as pre-med students can yield different findings from ours as well as prior work [16]. For example, in algebra-based physics courses, women are now the majority group, often making up $60 \%$ or more of the classroom. Further, the algebrabased physics courses are often selected by students interested in medicine and health-related professions. Similarly, the influence of the gender of the instructor on identity development can be another factor to investigate further, especially regarding the role of perceived recognition. In particular, recognition by a TA or instructor of similar gender may matter to a different extent than recognition by a TA or instructor of a different gender.

\section{ACKNOWLEDGMENTS}

This work was supported by Grant No. DUE-1524575 from the National Science Foundation and Grant No. 220020483 from the James S. McDonnell Foundation. Portions of these results were presented at the American Association of Physics Teachers Summer Meeting and Physics Education Research Conference. We would like to thank Kyle Whitcomb for his contributions during the data analysis. Finally, we would also like to thank Dr. Robert Devaty for his constructive feedback on the manuscript.

\section{APPENDIX: MODERATION ANALYSIS WITH MULTIGROUP SEM}

We did a moderation analysis to test the group differences in the path analysis. We used the R software 
package "lavaan" to conduct multigroup SEM. We initially tested for measurement invariance. In other words, we looked at whether the factor loadings, intercepts, and residual variances of the observed variables are equal in the model where we measure the latent constructs so we can confidently perform multigroup analysis. The analysis involves introducing certain constraints in steps and testing the model differences from the previous step. In each step, we compare the model to both the previous step and the freely estimated model, that is, the model where all parameters are freely estimated for each gender group. First, to test for "weak" or "metric" measurement invariance, we ran the model where only factor loadings were fixed to equality across both gender groups, but intercept and errors were allowed to differ. The model was not statistically significantly different than the freely estimated model according to a likelihood ratio test, so weak measurement invariance holds when we compared to freely estimated model where chi-square difference $\left(\Delta \chi^{2}\right)=5.02$, degree of freedom difference $(\Delta \mathrm{df})=10$, and nonsignificant $p$ value $=0.88$. Next, we tested for "strong" or "scalar" measurement invariance by fixing both factor loadings and intercepts to equality across gender groups. This model was not statistically significantly different than either the metric invariance model $\left(\Delta \chi^{2}=12.264, \Delta \mathrm{df}=10, p=0.2678\right)$ or the freely estimated model $\left(\Delta \chi^{2}=17.28, \Delta \mathrm{df}=20\right.$, $p=0.634$ ), so strong measurement invariance holds. Finally, to test for "strict" measurement invariance we fixed factor loadings, intercepts, and residuals to equality. In this step, there was a statistically significant difference from the previous models, therefore "strict invariance" did not hold when we compared to scalar measurement $\left(\Delta \chi^{2}=37.728\right.$, $\Delta \mathrm{df}=13, p=0.0003$ ). However, strict invariance is unlikely to hold in most situations. Therefore, since strong measurement invariance holds for this model, we continued on to perform other group comparisons.

Next, we ran a multigroup SEM where all regression estimates were fixed to equality for female and male students in addition to the factor loadings and intercepts and we compared this model with the freely estimated model. There was no statistically significant difference between the two models, so we report the model where regression pathways are equal for men and women. The model fit parameters for this case were not moderate but acceptable $\quad($ RMSEA $=0.082, \quad$ SRMR $=0.060, \quad$ CFI $=$ 0.930 , TLI $=0.924)$. The multigroup SEM results suggest that regression pathways (e.g., from competency beliefs to physics identity or interest to identity) did not show differences across gender when we compared to the freely estimated model $\left(\Delta \chi^{2}=25.86, \Delta \mathrm{df}=26, p=0.4707\right)$ or to the scalar model $\left(\Delta \chi^{2}=8.57, \Delta \mathrm{df}=6, p=0.1988\right)$. However, the means of the latent variables showed the same gender differences that are reported in the mediation model. That is, there were initially large differences in students' perceived recognition and slight differences in interest that mediated the effect of gender on identity.
[1] National Student Clearinghouse Research Center (2015). Science and Engineering Degree Attainment: 2004-2014, retrieved from https://nscresearchcenter.org/snapshotreportdegreeattainment $15 /$.

[2] National Science Board Science and Engineering Indicators, National Science Foundation Report, retrieved from website https:/www.nsf.gov/statistics/2018/nsb20181/digest/ sections/preface.

[3] https://www.aip.org/statistics/data-graphics/percent-physicsbachelors-and-phds-earned-women-classes-1975-through2016.

[4] Women, Minorities, and Persons with Disabilities in Science, and Engineering, Occupation (2017). retrieved from https://nsf.gov/statistics/2017/nsf17310/digest/occupation/ women.cfm.

[5] P. V. Engelhardt, in Getting started in PER, Reviews in PER Vol. 2, edited by C. Henderson and K. A. Harper (American Association of Physics Teachers, College Park, MD, 2009).

[6] E. Seymour, Tracking the processes of change in US undergraduate education in science, mathematics, engineering, and technology, Sci. Educ. 86, 79 (2002).
[7] V. Sawtelle, E. Brewe, and L. Kramer, Exploring the relationship between self-efficacy and retention in introductory physics, J. Res. Sci. Teach. 49, 1096 (2012).

[8] E. Marshman, Z. Y. Kalender, C. Schunn, T. NokesMalach, and C. Singh, A longitudinal analysis of students' motivational characteristics in introductory physics courses: Gender differences, Can. J. Phys. 96, 391 (2018).

[9] Z. Hazari, R. H. Tai, and P. M. Sadler, Gender differences in introductory university physics performance: The influence of high school physics preparation and affective factors, Sci. Educ. 91, 847 (2007).

[10] H. B. Carlone and A. Johnson, Understanding the science experience of successful women of color: Science identity as an analytical lens, J. Res. Sci. Teach. 44, 1187 (2007).

[11] Z. Hazari, G. Sonnert, P. Sadler, and M. Shanahan, Connecting high school physics experiences, outcome expectations, physics identity, and physics career choice: A gender study, J. Res. Sci. Teach. 47, 978 (2010).

[12] Z. Hazari, G. Potvin, R. Lock, F. Lung, G. Sonnert, and P. Sadler, Factors that affect the physical science career interest of female students: Testing five common hypotheses, Phys. Rev. ST Phys. Educ. Res. 9, 020115 (2013). 
[13] Z. Hazari, P. Sadler, and G. Sonnert, The science identity of college students: Exploring the intersection of gender, race, and ethnicity, J. Coll. Sci. Teach. 42, 82 (2013).

[14] C. Monsalve, Z. Hazari, D. McPadden, G. Sonnert, and P. Sadler, Examining the relation between career outcome expectations and physics identity, in Proceedings of the 2016 Physics Education Research Conference, Sacramento, CA (AIP, New York, 2016), pp. 228-231.

[15] G. Potvin and Z. Hazari, The development and measurement of identity across the physical sciences, in Proceedings of the 2013 Physics Education Research Conference, Portland, OR (AIP, New York, 2013), pp. 281-284.

[16] A. Godwin, G. Potvin, Z. Hazari, and R. Lock, Identity, critical agency, and engineering: An affective model for predicting engineering as a career choice, J. Engin. Educ. 105, 312 (2016).

[17] STEM attrition: College students' paths into and out of STEM fields, Statistical Analysis Report, retrieved from https://nces.ed.gov/pubs2014/2014001rev.pdf.

[18] E. Seymour and N. M. Hewitt, Talking about Leaving: Why Undergraduates Leave the Sciences (Westview Press, Boulder, CO 1997).

[19] L. Bian, S. J. Leslie, and A. Chimpian, Gender stereotypes about intellectual ability emerge early and influence children's interest, Science 355, 389 (2017).

[20] S. J. Leslie, A. Chimpian, M. Meyer, and E. Freeland, Women are underrepresented in disciplines that emphasize brilliance as the key to success, Science 347, 262 (2015).

[21] S. Upson and L.F. Friedman, Where are the female geniuses?, Sci. Am. Mind 23, 63 (2012).

[22] L. Archer, J. Moote, B. Francis, J. DeWitt, and L. Yeomans, The "Exceptional" physics girl: A sociological analysis of multimethod data from young women aged 10-16 to explore gendered patterns of post-16 participation, Am. Educ. Res. J. 54, 88 (2017).

[23] C. Steele and J. Aronson, Stereotype threat and the intellectual test performance of African Americans, Attitudes Soc. Cogn. 69, 797 (1995).

[24] G. C. Marchand and G. Taasoobshirazi, Stereotype threat and women's performance in physics, Int. J. Sci. Educ. 35, 3050 (2013).

[25] A. Maries and C. Singh, Stereotype threat? Effects of inquiring about test takers' gender on conceptual test performance in physics, AIP Conf. Proc. 1697, 120008 (2015).

[26] C. A. Moss-Racusin, J. F. Dovidio, V. L. Brescoll, M. J. Graham, and J. Handelsman, Science faculty's subtle gender biases favor male students, Proc. Natl. Acad. Sci. U.S.A. 109, 16474 (2012).

[27] A. T. Danielsson, Exploring woman university physics students 'doing gender' and 'doing physics', Gender Educ. 24, 25 (2012).

[28] C. Hill, C. Corbett, and A. Rose, Why so few? Women in science, technology, engineering, and mathematics (2010). Retrieved from https:/www.aauw.org/files/2013/02/WhySo-Few-Women-in-Science-Technology-Engineering-andMathematics.pdf.

[29] J. Day, J. B. Stang, N. G. Holmes, D. Kumar, and D. A. Bonn, Gender gaps and gendered action in a first-year physics laboratory, Phys. Rev. Phys. Edu. Res. 12, 020104 (2016).

[30] M. Wang and J. Degol, Motivational pathways to STEM career choices: using expectancy-value perspective to understand individual and gender differences in STEM fields, Dev. Rev. 33, 304 (2013).

[31] C. Dweck, Mindset: The New Psychology of Success (Ballentine, New York, 2006); Self-theories: Their Role in Motivation, Personality, and Development (Psychology Press, Philadelphia, 1999).

[32] L. Blackwell, K. Trzesniewski, and C. Dweck, Implicit theories of intelligence predict achievement across an adolescent transition: A longitudinal study and an intervention, Child Development 78, 246 (2007).

[33] V. Tinto, Classrooms as communities: Exploring the educational character of student persistence, J. Higher Educ. 68, 599 (1997).

[34] J. Blickenstaff, Women and science careers: Leaky pipeline or gender filter?, Gender Educ. 17, 369 (2005).

[35] R. Ivie and K. Stowe, Women in Physics 2000 (American Institute of Physics Rep. No. R-430) (American Institute of Physics, Washington, DC, 2000).

[36] B. Zimmerman, Self-efficacy: An essential motive to learn, Contemp. Educ. Psychol. 25, 82 (2000).

[37] P. Pintrich, A motivational science perspective on the role of student motivation in learning and teaching contexts, J. Educ. Psychol. 95, 667 (2003).

[38] T. Bouffard-Bouchard, S. Parent, and S. Larivee, Influence of self-efficacy on self-regulation and performance among junior and senior high-school aged students, Int. J. Behav. Dev. 14, 153 (1991).

[39] W. K. Adams, K. K. Perkins, N. S. Podolefsky, M. Dubson, N. D. Finkelstein, and C. E. Wieman, New instrument for measuring student beliefs about physics and learning physics: The Colorado Learning Attitudes about Science Survey, Phys. Rev. ST Phys. Educ. Res. 2, 010101 (2006).

[40] E. Redish, J. Saul, and R. Steinberg, Student expectations in introductory physics, Am. J. Phys. 66, 212 (1998).

[41] K. Edmondson and J. Novak, The interplay of scientific epistemological views, learning strategies, and attitudes of college students, J. Res. Sci. Teach. 30, 547 (1993).

[42] T. Nokes-Malach, E. Marshman, Z. Y. Kalender, C. Schunn, and C. Singh, Investigation of male and female students' motivational characteristics throughout an introductory physics course sequence, in Proceedings of the 2017 Physics Education Research Conference, Cincinnati, OH, 2018, pp. 276-279, https://doi.org/10.1119/ perc.2017.pr.064.

[43] T. Nokes-Malach, Z. Y. Kalender, E. Marshman, C. Schunn, and C. Singh, The impact of prior preparation and motivational characteristics on learning outcomes in introductory physics courses, in Proceedings of the 2018 Physics Education Research Conference, Washington, DC, 2019, https://doi.org/10.1119/perc.2018.pr.Nokes-Malach.

[44] J. M. Nissen and J. T. Shemwell, Gender, experience, and self-efficacy in introductory physics, Phys. Rev. Phys. Educ. Res. 12, 020105 (2016).

[45] C. Lindstrøm and M. D. Sharma, Self-efficacy of first year university physics students: Do gender and prior formal 
instruction in physics matter?, Int. J. Innovation Sci. Math. Educ. 19, 1 (2011).

[46] Z. Y. Kalender, E. Marshman, T. Nokes-Malach, C. Schunn, and C. Singh, Large gender differences in physics self-efficacy at equal performance levels: A warning sign?, in Proceedings of the 2018 Physics Education Research Conference, Washington, DC, 2018, https://doi.org/ 10.1119/perc.2018.pr.Kalender.

[47] E. Marshman, Z. Y. Kalender, T. Nokes-Malach, C. Schunn, and C. Singh, Female students with A's have similar self-efficacy as male students with C's in introductory courses: A cause for alarm?, Phys. Rev. Phys. Educ. Res. 14, 020123 (2018).

[48] P. Haussler and L. Hoffmann, An intervention study to enhance girls' interest, self-concept and achievement in physics class, J. Res. Sci. Teach. 39, 870 (2002).

[49] G. Kortemeyer, Correlations between student discussion behavior, attitudes, and learning, Phys. Rev. Phys. ST Educ. Res. 3, 010101 (2007).

[50] M. Lorenzo, C. Crouch, and E. Mazur, Reducing the gender gap in the physics classroom, Am. J. Phys. 74, 118 (2006).

[51] E. Brewe and V. Sawtelle, Modeling instruction for university physics: examining the theory in practice, Eur. J. Phys. 39, 054001 (2018).

[52] A. Miyake, L. E. Kost-Smith, N. D. Finkelstein, S. J. Pollock, and G. L. Cohen, Reducing the gender achievement gap in college science: A classroom study of values affirmation, Science 330, 1234 (2010).

[53] J. P. Gee, Identity as an analytical lens for research in education, Rev. Res. Educ. 25, 99 (2000).

[54] J. E. Stets and P. J. Burke, A sociological approach to self and identity, in Handbook of Self and Identity, edited by M. R. Leary and J. P. Tangney (Guilford Press, 2003), pp. 128-152.

[55] Z. Hazari, C. Cass, and C. Beattie, Obscuring power structures in the physics classroom: Linking teacher positioning, student engagement, and physics identity development, J. Res. Sci. Teach. 52, 735 (2015).

[56] R. M. Rock, Z. Hazari, and G. Potvin, Physics Career Intentions: The Effect of Physics Identity, Math Identity, and Gender, in Proceedings of the 2012 Physics Education Research Conference, Philadelphia, PA (AIP, New York, 2012).

[57] A. Bandura, Social cognitive theory of self-regulation, Organ. Behav. Human Decision Processes 50, 248 (1991).

[58] S. L. Britner and F. Pajares, Sources of science self-efficacy beliefs of middle school students, J. Res. Sci. Teach. 43, 485 (2006).

[59] A. L. Zeldin, S. L. Britner, and F. Pajares, A comparative study of the self-efficacy beliefs of successful men and women in mathematics, science, and technology careers, J. Res. Sci. Teach. 45, 1036 (2008).

[60] R. Lapan, A. Adams, S. Turner, and J. Hinkelman, Seventh graders' vocational interest and efficacy expectation patterns, J. Career Develop. 26, 215 (2000).

[61] D. Schunk and F. Pajares, The development of academic self-efficacy, in Development of Achievement Motivation: A Volume in the Educational Psychology Series, edited by
A. Wigfield and J. Eccles (Academic Press, San Diego, CA 2002), pp. 15-31.

[62] P. Haussler and L. Hoffmann, An intervention study to enhance girls' interest, self-concept, and achievement in physics class, J. Res. Sci. Teach. 39, 870 (2002).

[63] A. Wigfield and J. S. Eccles, The development of achievement task values: A theoretical analysis, Developmental Rev. 12, 256 (1992).

[64] S. Hidi, Interest: A unique motivational variable, Educ. Res. Rev. 1, 69 (2006).

[65] S. Hidi and K. A. Renninger, The four-phase model of interest development, J. Educ. Psychol. 41, 111 (2006).

[66] K. A. Renninger and S. Hidi, Revisiting the conceptualization, measurement and generation of interest, J. Educ. Psychol. 46, 168 (2011).

[67] S. E. Embretson and S. P. Reise, Item Response Theory for Psychologists (Psychology Press, Mahwah, NJ, 2000).

[68] F. Samejima, Estimation of Latent Ability Using a Response Pattern of Graded Scores, Psychometric Monograph, 17 (Psychometric Society, Richmond, VA 1969).

[69] https://www.stata.com/meeting/australia15/abstracts/ materials/oceania15_rosier.pdf.

[70] http://www.activationlab.org/tools/.

[71] J. Schell and B. Lukoff, Peer instruction competency belief instrument. Developed at Harvard University. Unpublished Instrument coetta. 2010.

[72] S. Glynn, P. Brickman, N. Armstrong, and G. Taasoobshirazi, Science motivation questionnaire II: Validation with science majors and nonscience majors, J. Res. Sci. Teach. 48, 1159 (2011).

[73] P. Vincent-Ruz and C. Schunn, The increasingly important role of science competency beliefs for science learning in girls, J. Res. Sci. Teach. 54, 790 (2017).

[74] R. C. MacCallum, M. W. Browne, and H. M. Sugawara, Power analysis and determination of sample size for covariance structure modeling, Psychological Methods 1, 130 (1996).

[75] D. Hooper, J. Coughlan, and M. Mullen, Structural equation modeling: Guidelines for determining model fit, Electronic J. Bus. Res. Methods 6, 53 (2008).

[76] R Core Team, R: A Language and Environment for Statistical Computing (R Foundation for Statistical Computing 2013), http://www.R-project.org/.

[77] J. Cohen, Statistical Power Analysis for the Behavioral Sciences (L. Erlbaum Associates, Hillsdale, NJ, 1998).

[78] R. M. Lock, Z. Hazari, and G. Potvin, Physics career intentions: The effect of physics identity, math identity, and gender, AIP Conf. Proc. 1513, 262 (2013).

[79] J. Wang and Z. Hazari, Promoting high school students' physics identity through explicit and implicit recognition, Phys. Rev. Phys. Educ. Res. 14, 020111 (2018).

[80] https://www.aps.org/programs/women/.

[81] https://www.aapt.org/aboutaapt/organization/women.cfm.

[82] E. Pollack, The only woman in the room: Why science is still a boys' club (Beacon Press, Boston, MA, 2015).

[83] https:/www.nytimes.com/2013/10/06/magazine/why-arethere-still-so-few-women-in-science.html.

[84] S. Buczynski and C. B. Hansen, Impact of professional development on teacher practice: Uncovering connections, 
Teach. Teach. Educ. 26, 599 (2010); C. C. Johnson and J. D. Fargo, Urban school reform enabled by transformative professional development: Impact on teacher change and student learning of science, Urban Educ. 45, 4 (2010); R. Santagata, N. Kersting, K. B. Givvin, and J. W. Stigler, Problem implementation as a lever for change: An experimental study of the effects of a professional development program on students' mathematics learning, J. Res. Educ. Effectiveness 4, 1 (2010).

[85] D. S. Yeager and G. M. Walton, Social-psychological interventions in education: They are magic, Rev. Educ. Res. 81, 267 (2011).

[86] J. M. Harackiewicz, E. A. Canning, Y. Tibbetts, S. J. Priniski, and J. S. Hyde, Closing achievement gaps with a utility-value intervention: Disentangling race and social class, J. Personal Soc. Psychol. 111, 745 (2016).

[87] G. M. Walton, C. Logel, J. M. Peach, S. J. Spencer, and M. P. Zanna, Two brief interventions to mitigate a "chilly climate" transform women's experience, relationship, and achievement in engineering, J. Educ. Psychol. 107, 468 (2015).

[88] K. R. Binning, N. Kaufmann, E. McGreevy, O. Fotuhi, S. Chen, E. Marshman, Z. Y. Kalender, L. Limeri, L. Betancur, and C. Singh, Changing social norms to foster the benefits of collaboration in diverse workgroups, unpublished manuscript, d-scholarship.pitt.edu/id/eprint/36006.

[89] M. Ong, T. L. Ko, and A. K. Hodari, Agency of women of color in STEM: Individual and institutional strategies for persistence and success, in Pathways, Potholes, and the Persistence of Women in Science: Reconsidering the Pipeline, edited by E.H. Branch (Lexington Books, Lanham, MD, 2016).

[90] R. Kachaf, L. Ko, A. Hodari, and M. Ong, Career-life balance for women of color: Experiences in science and engineering academia, J. Diversity Higher Educ. 8, 175 (2015).

[91] M. Ong, C. Wright, E. Espinosa, and G. Orfield, Inside the double bind: A synthesis of empirical research on undergraduate and graduate women of color in science, technology, engineering, and mathematics, Harv. Educ. Rev. 81, 172 (2011).

[92] M. Ong, The status of women of color in computer science, Communications of the ACM 54, 32 (2011).

[93] M. Ong, Challenging cultural stereotypes of 'scientific ability', in Everyday Antiracism: Getting Real about Race in School, edited by M. Pollock (New Press, New York 2008), pp. 114-119.

[94] G. Hackett and N. Betz, A self-efficacy approach to the career development of women, J. Vocat. Behav. 18, 326 (1981).

[95] C. Ganley, C. E. George, J. R. Cimpian, and M. B. Makowski, Gender equity in college majors: Looking beyond the STEM/Non-STEM dichotomy for answers regarding female participation, Am. Educ. Res. J. 55, 453 (2018).

[96] R. Lock and Z. Hazari, Discussing underrepresentation as a means to facilitating female students' physics identity development, Phys. Rev. Phys. Educ. Res. 12, 020101 (2016).

[97] R. Felder, G. Felder, M. Mauney, C. Hamrin, and E. Dietz, A longitudinal study of engineering student performance and retention. III. Gender differences in student performance and attitudes, J. Engin. Educ. 84, 151 (1995).

[98] C. S. Hulleman and J. M. Harackiewicz, Promoting interest and performance in high school science classes, Science 326, 1410 (2009). 